\title{
Eradication of Helicobacter pylori, as add-on therapy, has a significant, but temporary influence on recovery in chronic idiopathic urticaria: a placebo-controlled, double blind trial in the Polish population
}

\author{
Robert Pawłowicz, Krzysztof Wytrychowski, Bernard Panaszek \\ Department of Internal Medicine and Allergology, Wroclaw Medical University, Wroclaw, Poland
}

Adv Dermatol Allergol 2018; XXXV (2):151-155

DOI: https://doi.org/10.5114/ada.2018.75236

\begin{abstract}
Introduction: The infectious factor like Helicobacter pylori (HP) has been thought to trigger the vicious circle of chronic idiopathic urticaria (CIU), therefore its eradication could modify the course of the disease.

Aim: To reveal the influence of HP eradication on CIU clinical course.

Material and methods: Sixty-four CIU patients, receiving fexofenadine, as the basic treatment, took part in the research, divided into 3 groups: HP patients treated by eradication, HP patients receiving placebo, and patients without bacteria. Gastroscopy, urease test and histopathology were done to detect HP. Patients with HP were randomized and received eradication treatment or placebo. The efficacy of eradication was checked after 6 weeks by means of another gastroscopy, urease test and histopathology. In the $6^{\text {th }}$ week and in the $4^{\text {th }}$ and $6^{\text {th }}$ month after eradication, the symptoms were evaluated basing on the score symptom scale.

Results: Helicobacter pylori did not occur more frequently in CIU patients than in the healthy population. A statistically significant clinical improvement of CIU symptoms was observed in the $6^{\text {th }}$ week after eradication as compared to the group receiving placebo $(p=0.02)$ and patients who were not infected $(p=0.02)$. Further observation in the eradicated patients group revealed the rebound phenomenon - worsening of the clinical state $(p=0.001)$, which in the $4^{\text {th }}$ month did not differ from the patients not infected or patients receiving placebo.

Conclusions: Although HP occurs as frequently in CIU patients as in the healthy population, eradication, added to basic antihistaminic treatment, has a significant influence on CIU patients' recovery parallel to the reduction of stomach inflammation features.
\end{abstract}

Key words: chronic idiopathic urticaria, Helicobacter pylori, eradication.

\section{Introduction}

Urticaria is one of the most common skin diseases. Frequency of its occurrence varies from $12 \%$ to $15 \%$, some evaluate that it is even $23.5 \%$ of the whole population $[1,2]$. In chronic urticaria, skin lesions appear every day or almost every day for at least 6 weeks [3]. Chronic idiopathic urticaria (CIU) is a common ailment occurring mainly in adults. It appears in approximately $0.1 \%$ of the population and in $20 \%$ it retains for over 20 years. In children, however, it appears very rarely [4]. Research on the CIU patients' quality of life has shown that disturbances in professional, private, and social life are comparable to decreasing of the quality of life in these areas in severe heart ischemia patients [5]. Hence, many scientists' ef- forts, among others, lead to discovering the cause of this chronic disease.

The data in reference papers indicating the probability of relation between CIU and Helicobacter pylori (HP) infection have appeared in recent years [3, 4]. Helicobacter pylori infection occurrence is related mainly to the socio-economic status and increases with age. In developing countries it fluctuates between $80 \%$ and almost $100 \%$, whereas in developed countries (Western Europe, United States of America, Australia) it is $20 \%$ to $40 \%$. Poland belongs to in-between countries with the infection rate of $40 \%$ to $60 \%$ of the population [6].

The treatment of HP infection is usually based on combined, seven days' therapy consisting of 3 medi-

Address for correspondence: Robert Pawłowicz MD, PhD, Department of Internal Medicine and Allergology, Wroclaw Medical University, 66 M. Curie-Skłodowskiej St, 50-369 Wroclaw, Poland, phone/fax: +48 7178425 21, +48 7132709 54, e-mail: robert.pa@wp.pl Received: 9.12.2016, accepted: 26.01.2017. 
cines, namely proton pump inhibitors, and two antibiotics which are supposed to eradicate the bacteria. The endoscopic examination combined with the urease test and histopathological examination of stomach mucous membrane samples is widely accepted in HP infection diagnosis [7, 8].

Chronic idiopathic urticaria is currently considered to be multifactorial complex disease with contribution of unidentifiable internal factors among which HP may be taken into consideration [3]. Hence, the objective of our study was to reveal the influence of eradication of HP on the clinical course of CIU. Especially, the short-term and long-term effect of eradication of HP on improving symptoms of disease was evaluated in this trial.

\section{Aim}

The aim of the study was to evaluate the effect of eradication of HP on the clinical course of CIU.

\section{Material and methods}

Patients with urticaria symptoms persisting for longer than 6 weeks were included in the trial in order to evaluate the influence of eradication treatment of HP on the course of the CIU, compared to basic/standard antihistamine treatment and placebo control. After the interview and physical examination, typical laboratory diagnostic tests were performed to detect CIU potential etiopathogenetic factor. In order to do this, infectious/ inflammatory sites were searched for in the whole body by thorough physical, radiological and laboratory tests, including bacteriological tests, complete blood cell count and markers of systemic inflammation (C-reactive protein - CRP, erythrocyte sedimentation rate - ESR). Antinuclear antibodies, anti-neutrophilic-cytoplasmic antibodies, TSH, anti-thyroid antibodies (anti-thyroglobulin antibodies - anti-TG, anti-thyroid peroxidase antibodies - anti-TPO) the concentration of complement constituents C3 and C4 in serum, total IgE, eosinophilia in blood were also carried out. Moreover, skin prick tests were done on inhalation and food allergens, exposure trials to physical stimuli (cold, warmth, pressure, vibration, irrita-

Table 1. Clinical urticaria intensity evaluation

\begin{tabular}{ll}
\hline $\begin{array}{l}\text { Score } \\
\text { Symptom } \\
\text { Scale }\end{array}$ & Urticarial weal \\
\hline 0 & None \\
\hline 1 & Mild $(<20$ weals $/ 24 \mathrm{~h})$ \\
\hline 2 & Moderate $(20-50$ weals $/ 24 \mathrm{~h})$ \\
\hline 3 & $\begin{array}{l}\text { Intensive }(>50 \text { weals } / 24 \mathrm{~h} \text {, or large spreading } \\
\text { weals })\end{array}$ \\
\hline
\end{tabular}

tion) as well as provocation trial with acetylsalicylic acid. Treatment with fexofenadine was stopped at least 3 days before those tests, when it was impossible we based on data from medical history. Patients in whom the abovementioned diagnostic tests remained within normal limits had gastroscopy and the urease test as well as HP histopathology. If HP presence was confirmed by both tests, the patients were randomized into 2 groups. One of them received a 7-day eradication treatment: omeprazole $20 \mathrm{mg}$ once a day and amoxicillin $1 \mathrm{~g}$ as well as clarithromycin 500 mg twice a day. At the same time the second group received placebo. The principle of the double blind trial was applied in this case, when neither a doctor nor a patient were aware whether they receive medicines or placebo. To evaluate the efficacy of the treatment after 6 weeks, another gastroscopy was done along with a quick urease test and HP histopathology. If both tests were negative, the eradication was thought effective. The third group comprised CIU patients who did not reveal HP infestation. All patients received the same urticaria treatment - fexofenadine $180 \mathrm{mg}$ once a day.

The clinical control of the urticaria symptoms was evaluated by one doctor before patient's inclusion into the trial (t0), in the $6^{\text {th }}$ week (t1), in the $4^{\text {th }}$ month (t2) and in the $6^{\text {th }}$ month (t3) after eradication. Skin lesions were estimated with the scale (0 to 3 score symptoms) according to Table 1 . The patients treated 4 weeks before randomization with proton pump inhibitors, antibiotics, pregnant women, patients with severe somatic and mental ailments, with contraindication to gastroscopy and eradication treatment were excluded from the trial.

The Bioethical Committee (No. KB-936/2003) at the Wroclaw Medical University permitted the research.

\section{Statistical analysis}

For statistical analysis of results, the $\chi^{2}$ test, Mc Nemara test, two-factor analysis of repeated variation and post-choc Tukey's LSD were applied. Factors of two-factor variation analysis were the examined group and the time of examination; $p<0.05$ was thought statistically significant. Calculations were done with the help of B. Rosner Biostatistics, Duxbury 2000.

\section{Results}

Sixty-four patients took part in the trial including 36 (56.2\%) women and 28 (43.7\%) men. The average age of patients was $42.8 \pm 13.3$ years. Helicobacter pylori was detected in 48 (75\%) participants. Those patients were randomized into 2 groups: placebo and eradication group, each group including 24 subjects. In the placebo group, a group receiving eradication and the HP negative group (16 patients) there were no significant statistical discrepancies as far as patients' age, sex, existing gastroscopic features of chronic gastritis or gastro-esophageal reflux were concerned. Eradication was ineffective (posi- 
Table 2. Characteristics of the groups

\begin{tabular}{lccccc}
\hline Parameter & $\begin{array}{c}\text { Placebo } \\
\boldsymbol{N}=\mathbf{2 4}\end{array}$ & $\begin{array}{c}\text { Eradication } \\
\boldsymbol{N}=\mathbf{2 4}\end{array}$ & $\begin{array}{c}\text { HP-negative } \\
\boldsymbol{N}=16\end{array}$ & $\begin{array}{c}\text { Whole group } \\
\boldsymbol{N}=64\end{array}$ & $\boldsymbol{P}_{\text {-value* }}$ \\
\hline $\begin{array}{l}\text { Age } \\
\text { fyears } \\
x \pm \mathrm{SD}\end{array}$ & $43.54 \pm 14.28$ & $42.54 \pm 12.62$ & $42.19 \pm 13.45$ & $42.83 \pm 13.27$ & 0.94 \\
\hline $\begin{array}{l}\text { Female } \\
n(\%)\end{array}$ & $13(54.17)$ & $11(45.83)$ & $12(75.00)$ & $36(56.25)$ & 0.18 \\
\hline $\begin{array}{l}\text { Male } \\
n(\%)\end{array}$ & $11(45.83)$ & $13(54.17)$ & $4(25.00)$ & $28(43.75)$ & 0.18 \\
\hline $\begin{array}{l}\text { Gastr. } \\
n(\%)\end{array}$ & $19(79.17)$ & $22(91.67)$ & $13(81.25)$ & $54(84.38)$ & 0.25 \\
\hline $\begin{array}{l}\text { Refl. } \\
n(\%)\end{array}$ & $10(41.67)$ & $16(66.67)$ & $12(75.00)$ & $38(59.38)$ & 0.07 \\
\hline
\end{tabular}

$N$ - group number, Gastr. - presence of stomach mucous membrane infection symptoms in gastroscopy, Refl. - reflux symptoms in gastroscopy, $x$ - average, $S D-$ standard deviation, $p^{*}-\chi^{2}$ test.

tive control urease test and histopathology) in 2 (7.7\%) patients (Table 2).

In the group of eradicated patients, confirmed by gastroscopy and negative urease test there was a statistically significant $(p=0.02)$ decrease in the number of subjects revealing the features of chronic stomach mucous membrane infection: from 22 (91.7\%) before to 15 (62.5\%) after eradication. Parallel to the observation described above the results of the statistical analysis disclosed a statistically significant decrease in symptoms based on the skin score scale in the group of eradicated patients, compared to the group receiving placebo ( $p=$ $0.02)$ and the group without HP infection $(p=0.02)$. But this positive effect of paramount improvement in skin lesions was observed in the $6^{\text {th }}$ week after eradication and next, from this cut-point, improvement of hives became gradually weaker during follow up control in the $4^{\text {th }}$ and $6^{\text {th }}$ month. In the group of HP positive patients undergoing eradication, there was shown a statistical importance for the time parameter $(p<0.001)$, which means the decrease in the skin score symptoms between t0 and t1 (in the first 6 weeks) and aggravation of symptoms between $t 1$ and $t 2$ later on (Figure 1).

\section{Discussion}

Results obtained in this study indicate the importance of doing the HP test in every case of CIU and introduced eradication in HP patients, as well as monitoring the state of the upper part of the digestive tract. What seems to be interesting in the presented work (Figure 1) is the rebound phenomenon that is very slow aggravation of symptoms, in spite of effective eradication, in the $6^{\text {th }}$ week of observation which, according to our knowledge, has not been so far presented in publications available in MEDLINE database. The worsening of the clinical state was connected probably with reinfection or relapsing of infection. Therefore patients who clinical urticaria course worsened after

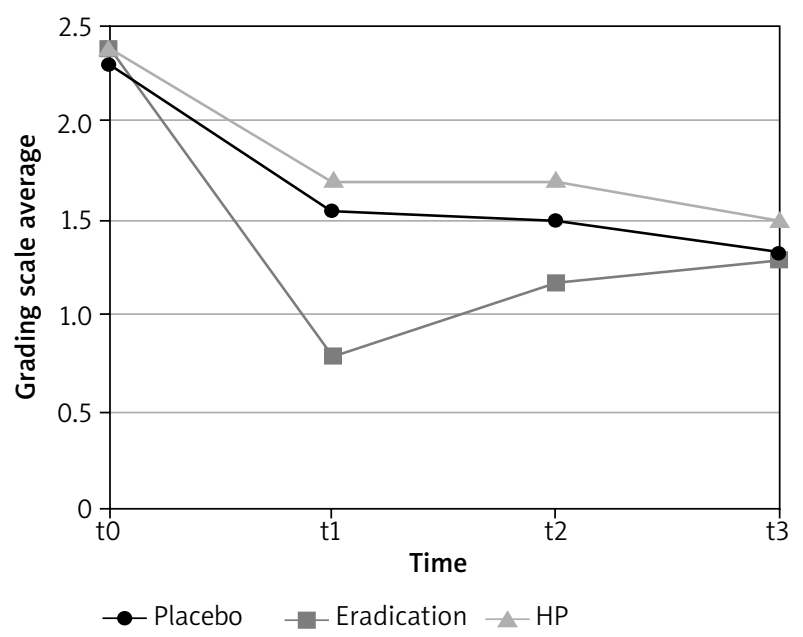

to - before including into the research, $t 1$ - control visit 6 weeks after eradication, $t 2$ - control visit after 4 months, $t 3$ - control visit after 6 months.

Figure 1. Diagram of skin symptoms score - grading scale average during consecutive control visits

eradication may be eradicated once more to obtain longer remission, but reinfection must be confirmed by reliable laboratory tests (e.g. gastroscopy and urease test). Reinfection in countries where HP infection does not spread widely (e.g. the USA), is rare (1\%) [7]. It is well known that HP reinfection has occurred in $12.5 \%$ to $50 \%$ of cases during the first year after eradication in Poland [8]. It was stated that the bacteria might be eradicated from the stomach but at the same time survive in other parts of the digestive tract, most often in the oral cavity and from this site may move to the stomach again [9].

Frequency of HP infection is connected mainly with the socio-economic status of the society. Therefore, data obtained in this research were compared to the frequency of HP occurring in the population in Lower Sile- 
sia, which is $73 \%$ and does not differ greatly from data obtained in the presented work (75\%) $(p=0.7)$ [10]. The lack of difference in the frequency of HP infection among $\mathrm{CIU}$ patients compared to the general population of a given area does not need to exclude the role of the bacteria in CIU pathogenesis. Bacteria may act as a triggering factor of the cascade of pathophysiological processes resulting in the appearance of CIU, and these processes may continue even when bacteria is no longer in the organism. It may be a consequence of, for example, induction of synthesis IL-8 found in HP infection. IL-8 affects mainly neutrophils, but may also work chemotactically on eosinophils and, in this manner, also play an important role in appearing and maintaining skin lesions in CIU [11].

There are some other interesting hypotheses describing how HP infection may lead to mast cells activation, which plays a crucial role in CIU pathogenesis. Several studies have demonstrated that a few of HP proteins for example vacuolating cytotoxin A (VacA) and neutrophilactivating protein (NAP) are able to activate mast cells directly $[12,13]$. A recently published study by Tan et al. [14] has shown that 21-35 kDa mixed protein component extracted from $\mathrm{HP}$ can stimulate the release of histamine, TNF- $\alpha$, IL-3, IFN- $\gamma$, and LTB4 by LAD2 subtype of mast cells in a dose-dependent or time-dependent manner.

The results of trials published so far have been ambiguous. Some of them [15-25] have confirmed the relation between HP and CIU, the other [26-32] deny the fact, hence comparing the results is difficult first of all, because of discrepancies in frequency of HP infection occurrence, different schemes of eradication, no confirmation of efficacy of eradication, no appropriate control groups, and finally clinical controls in different time frames. A systematic review of existing studies done by Federman et al. [22] has disclosed a statistically significant relation between HP eradication and CIU remission, however another one done by Shakouri et al. [33] has shown no strong evidence that HP eradication leads to improvement of CIU symptoms. Meta-analysis of observational studies, published in Medline and EMBASE up to July 2014, has suggested a significant but weak correlation between HP infection and a risk of CIU development [24]. Only a few studies [20, 30] that has been done so far were designed as double blind trials with placebo. In one of them done by Gaig et al. [20], the improvement of the clinical state was observed after eradication, in the other, published by Schnyder et al. [30] there were no statistically significant differences in the clinical course of CIU between the observed groups. Nevertheless, there were small groups of patients, only 3 in the eradicated group and 8 in the control group at the end of the study, what could influence the final conclusions.

The study presented in this article has some limitations. The most important of them, in our opinion, is the short time of patients' observation, lack of evaluation of $\mathrm{HP}$ reinfection, and a small number of patients recruited into the study. All of them may have a disadvantageous effect on outcomes of our study.

\section{Conclusions}

Despite the lack of confirmation of higher frequency of HP infection in CIU patients, those who were eradicated effectively had revealed an improvement in the clinical course of the disease until the first control visit in the $6^{\text {th }}$ week after eradication. This effect has been slowly decreasing in further observation showing greatest dynamics in the period between the $6^{\text {th }}$ and the $8^{\text {th }}$ week of the observation. This could be related to HP reinfection or relapse (what was not confirmed in our study). Considering what was mentioned above, it seems to be important to examine CIU patients for HP infection and, when it is confirmed, applying eradication to them. But the results of our research suggest also that patients who improve very significantly after eradication, in case of further CIU exacerbation should be diagnosed for HP again and in case of positive tests confirming infection, another eradication should be planned. If the followed eradication decrease the symptoms again - the HP diagnosis and eradication can be considered as add-on therapy to standard chronic urticaria diagnosis and treatment. Recently emerging mastocyte/basophil priming phenomenon, as a feature of CIU and consequence of autoreactive IgE against several HP internal factors may provide a new insight into pathogenesis of this complex syndrome [34].

\section{Conflict of interest}

The authors declare no conflict of interest.

\section{References}

1. Champion RH, Roberts SOB, Carpenter RG, Roger JH. Urticaria and angioedema: a review of 554 patients. Br J Dermtol 1969; 81: 588-97.

2. Swinny B. The atopic factor In urticaria. South Med J 1941; 34: 855-8

3. Zuberbier T, Aberer W, Asero R, et al. The EAACI/GA(2) LEN/ EDF/WAO Guideline for the definition, classification, diagnosis, and management of urticaria: the 2013 revision and update. Allergy 2014; 69: 868-87.

4. Graves MW. Pathophysiology of chronic urticaria. Int Arch Allergy Immunol 2002; 127: 3-9.

5. O’Donnell BF, Lawflor F, Simpson J, et al. The impact of urticaria on quality of life. Br J Dermatol 1997; 136: 197-201.

6. Perez-Perez G, Rothenbacher D, Brenner H. Epidemiology of H. pylori infection. Helicobacter 2004; 9 (Suppl. 1): 1-6.

7. Abu-Mahfouz MZ, Prasad VM, Santogade P, et al. Helicobacter pylori recurrence after successful eradication: 5-year follow-up in the United States. Am J Gastroenterol 1997; 92 : 2025-8.

8. Jarczyk G, Jarczyk J, Raczyńska A. Triple therapy for eradication $\mathrm{H}$. pylori reducing the peptic ulcer recurrence rate. A 12-month follow-up study. Gastroenterol Pol 1997; 4: 53-9. 
9. Miyabayashi H, Furihata K, Shimuzu T, et al. Influence of oral Helicobacter pylori on the success of eradication therapy against gastric Helicobacter pylori. Helicobacter 2000; 5: 30-7.

10. Matysiak-Budnik T, Knapik Z, Megraud F, et al. Helicobacter pylori infection in Eastern Europe; seroprevalence in the Polish population of Lower Silesia. Am J Gastroenterol 1998; 91: 2513-5.

11. Lindholm C, Quiding-Jarbrink M, Lonroth H, et al. Local cytokine response in Helicobacter pylori-infected subjects. Infect Immunol 1998; 66: 5964-71.

12. Supajatura V, Ushio H, Wada A, et al. Cutting edge: VacA, a vacuolating cytotoxin of Helicobacter pylori, directly activates mast cells for migration and production of proinflammatory cytokines. J Immunol 2002; 168: 2603-7.

13. Tsai CC, Kuo TY, Hong ZW, et al. Helicobacter pylori neutrophil-activating protein induces release of histamine and interleukin-6 through G protein-mediated MAPKs and PI3K/ Akt pathways in HMC-1 cells. Virulence 2015; 6: 755-65.

14. Tan RJ, Sun HQ, Zhang W, et al. A 21-35 kDa mixed protein component from Helicobacter pylori activates mast cells effectively in chronic spontaneous urticaria. Helicobacter 2016; 21: 565-74.

15. Rojo-Garcia JM, Muńoz-Pérez MA, Escudero J, et al. Helicobacter pylori in rosacea and chronic urticaria. Acta Derm Venereol 2000; 80: 156-7.

16. Wedi B, Wagner S, Werfel T, et al. Prevalence of Helicobacter pylori-associated gastritis in chronic urticaria. Int Arch Allergy Immunol 1998; 116: 288-94.

17. Radenhausen M, Schulzke JD, Geilen CC, et al. Frequent presence of Helicobacter pylori infection in chronic urticaria. Acta Derm Venereol 2000; 80: 48-9.

18. Di Campli C, Gasbarrini A, Nucera E, et al. Beneficial effects of Helicobacter pylori eradication on idiopathic chronic urticaria. Dig Dis Sci 1998; 43: 1226-9.

19. Shiotani A, Okada K, Yanaoka K, et al. Beneficial effect of Helicobacter pylori eradication in dermatologic diseases. Helicobacter 2001; 6: 60-5.

20. Gaig P, Garcia-Ortega P, Enrique E, et al. Efficacy of eradication of Helicobacter pylori infection in patients with chronic urticaria. A placebo-controlled double blind study. Allergol Immunopathol 2002; 30: 255-8.

21. Fukuda S, Shiomyama T, Umegaki N, et al. Effect of Helicobacter pylori eradication in the treatment of Japanese patients with chronic idiopathic urticaria. J Gastroenterol 2004; 39: 827-30.

22. Federman DG, Kirsner RS, Moriarty JP, et al. The effect of antibiotic therapy for patients infected with Helicobacter pylori who have chronic urticaria. I Am Acad Dermatol 2003; 49: 861-64.

23. Akashi R, Ishiguro N, Shimuzu S, et al. Clinical study of the relationship between Helicobacter pylori and chronic urticaria and prurigo chronica multiformis: effectiveness of eradication therapy for Helicobacter pylori. J Dermatol 2011; 38: 761-6.

24. Gu H, Li L, Gu M, et al. Association between Helicobacter pylori infection and chronic urticaria: a meta-analysis. Gastroenterol Res Pract 2015; 2015: 486974.

25. Mogaddam MR, Yazdanbod A, Ardabili NS, et al. Relationship between Helicobacter pylori and idiopathic chronic urticaria: effectiveness of Helicobacter pylori eradication. Postep Derm Alergol 2015; 32: 15-20.

26. Ozakaya-Bayazit E. Helicobacter pylori eradication in patients with chronic urticaria. Arch Dermatol 1998; 134: 1165-6.
27. Hook-Nikanne J, Varjonen E, Harvima RJ, et al. Is Helicobacter pylori infection associated with chronic urticaria? Acta Derm Venereol 2000; 80: 425-6.

28. Wustlich S, Brehler R, Luger TA, et al. Helicobacter pylori as a possible bacterial focus of chronic urticaria. Dermatology 1999; 198: 130-2.

29. Liutu M, Kalimo K, Uksila J, et al. Etiologic aspects of chronic urticaria. Int J Dermatol 1998; 37: 515-9.

30. Schnyder B, Helbling A, Pichler WJ. Chronic idiopathic urticaria: natural course and association with Helicobacter pylori infection. Int Arch Allergy Immunol 1999; 119: 60-3.

31. Hellmig S, Troch K, Ott SJ, et al. Helicobacter pylori infection in the treatment and outcome of chronic urticaria. Helicobacter 2008; 13: 341-5.

32. Curth HM, Dinter J, Nigemeier K, et al. Effects of Helicobacter pylori eradication in chronic spontaneous urticaria: results from a retrospective cohort study. Am J Clin Dermatol 2015; 16: 553-8.

33. Shakouri A, Compalati E, Lang DM, et al. Effectiveness of Helicobacter pylori eradication in chronic urticaria: evidencebased analysis using the Grading of Recommendations Assessment, Development, and Evaluation system. Curr Opin Allergy Clin Immunol 2010; 10: 362-9.

34. Panaszek B, Pawłowicz R, Grzegrzółka J, et al. Autoreactive IgE in chronic spontaneous/idiopathic urticaria and basophil/mastocyte priming phenomenon, as a feature of autoimmune nature of the syndrome. Arch Immunol Ther Exp (Warsz) 2017; 65: 137-43. 